\title{
LAS COOPERATIVAS NO AGROPECUARIAS Y LA TRANSFORMACIÓN ECONÓMICA EN CUBA: POLÍTICAS, PROCESOS Y ESTRATEGIAS
}

\author{
POR \\ Mirta VUOTTO2
}

\section{RESUMEN}

La contribución de las cooperativas se ha puesto en evidencia desde la década del 70 como principal línea de desarrollo en la producción agropecuaria de Cuba. En contraste, el reconocimiento de las cooperativas urbanas ha sido tardío, aun cuando fuese percibida la necesidad de transformaciones basadas en la realización de la propiedad en diversos escenarios territoriales.

El artículo analiza los procesos de reforma impulsados en Cuba desde la primera década de 2000 centrándose en las iniciativas tendientes a la promoción, constitución y desempeño de las cooperativas no agropecuarias (CNA).

Se examina el potencial y limitaciones propias de las experiencias recientes para reflexionar sobre los procesos y transformaciones organizacionales desde la perspectiva de sus miembros. A modo de conclusión el análisis plantea interrogantes acerca de la aptitud de estas cooperativas para sustraerse del impacto de circunstancias anteriores y sobre su capacidad para consolidar estrategias diseñadas por los cooperadores que tiendan a fortalecer los principios de adhesión voluntaria y autonomía en que se fundan estas organizaciones.

Palabras clave: Cooperativas no agropecuarias, Reformas Económicas, Cooperativas Urbanas, Nuevo Cooperativismo Cubano.

\footnotetext{
${ }^{1}$ Trabajo realizado en el marco del Programa de Cooperación Científico Tecnológica entre el Ministerio de Ciencia Tecnología e Innovación Productiva de la República Argentina (MINCYT) y el Ministerio de Ciencia, Tecnología y Medio Ambiente de la República de Cuba (CITMA).

2 Directora del Centro de Estudios de Sociología del Trabajo. Facultad de Ciencias Económicas. Universidad de Buenos Aires. Dirección de correo electrónico: mirta.vuotto@ fce.uba.ar.

REVESCO No 120 - Primer Cuatrimestre 2016 - ISSN: 1885-8031 - www.ucm.es/info/revesco

http://dx.doi.org/10.5209/rev_REVE.2016.v120.49697

Fecha de recepción: 04/03/2015

Fecha de aceptación: 14/05/2015
} 
Claves ECONLIT: P21, J54, P13.

\title{
NON-AGRICULTURAL CO-OPERATIVES AND ECONOMY TRANSFORMATION IN CUBA: POLITICS PROCESSES AND STRATEGIES
}

\begin{abstract}
Contribution of co-operatives has been demonstrated since the 1970s as the main development line in agricultural production in Cuba. In contrast, there has been a late recognition of urban co-operatives, even if the need of transformations based on the realization of property in different territorial scenarios had been identified.
\end{abstract}

The article analyses the reform processes launched since the first decade of the $21 \mathrm{st}$ century focusing on the nature of the initiatives fostering formation and promotion of nonagricultural co-operatives including follow up of their performance.

The potential and limitations of the recent experiences are examined in order to reflect on the organizational processes and transformations from the point of view of their members. To conclude, some questions are posed about whether these co-operatives are capable of avoiding the impact of earlier employment circumstances and of developing strategies aimed at reinforcing voluntary membership and autonomy on which they are founded.

Keywords: Non-Agricultural Cooperatives, Economic Reforms, Urban Cooperatives, New Cuban Cooperativism.

\section{INTRODUCCIÓN}

El reconocimiento del papel de las cooperativas en Cuba no es novedoso. Su contribución se ha puesto en evidencia desde la década del 70 como principal línea de desarrollo en la producción agropecuaria, del mismo modo que su incidencia en los cambios en la tenencia y el uso de la tierra y su mayor preparación respecto a la empresa estatal para funcionar bajo rigurosas condiciones de limitación de recursos. Frente a esta realidad, el reconocimiento de las cooperativas urbanas ha sido tardío, aún cuando fuese percibida la necesidad de transformaciones basadas en la realización de la propiedad en diversos escenarios territoriales. 
El artículo se propone analizar los procesos de reforma impulsados en Cuba desde la primera década de 2000 focalizando la naturaleza de las iniciativas tendientes a la constitución y promoción de las cooperativas no agropecuarias (CNA).

En la primera sección se examinan las reformas económicas iniciadas en 2008 que condujeron a la actualización del modelo socialista y resultan relevantes para el estudio del tema. Esas reformas permitieron plantear un modelo de gestión económica que incluye lineamientos específicos referidos a la nueva modalidad de cooperativas.

En la segunda sección se mencionan algunos antecedentes sobre el cooperativismo y su desarrollo en el país para abordar la etapa iniciada en 2010, el marco regulatorio en que se inscriben los procesos constitutivos de las CNA y el desempeño de las entidades autorizadas hasta 2014.

La tercera sección considera el potencial y limitaciones propias de las experiencias recientes para reflexionar luego sobre la particularidad de los procesos y transformaciones organizacionales desde la perspectiva de sus miembros. A modo de conclusión el análisis plantea el interrogante de si las cooperativas cubanas que han surgido de las reformas recientes pueden sustraerse del impacto de circunstancias anteriores que puedan determinar el camino a adoptar, o bien si existen condiciones para consolidar estrategias diseñadas por los propios cooperadores que tiendan a fortalecer los principios de adhesión voluntaria y autonomía en que se fundan estas organizaciones.

Los datos utilizados en el estudio proceden de fuentes estadísticas y documentales y de entrevistas personales, basadas en cuestionarios no estructurados, que fueron aplicadas a miembros del Consejo Administrativo de doce organizaciones localizadas en La Habana entre los meses de septiembre y noviembre de 2014. El objetivo de las entrevistas consistió en indagar el desempeño de las cooperativas desde su conformación ${ }^{3}$. Como fuente de información secundaria se consultaron los estatutos, los reglamentos internos y los planes anuales de producción y servicios de las cooperativas visitadas.

Se entrevistaron además profesionales de la Universidad de la Habana, del Instituto de

\footnotetext{
${ }^{3}$ Las actividades principales de las cooperativas visitadas son la reparación de vehículos automotores, la prestación de servicios complementarios para vehículos, la construcción y mantenimiento de edificios, la venta al por menor en mercados agropecuarios, el pesaje, el transporte regular de pasajeros por vía terrestre y la creación de obras seriadas en el campo de la plástica. Ocho de las entrevistas fueron realizadas por la doctoranda Liliana Ripoll
} 
Filosofía de Cuba, del Centro de Investigaciones Psicológicas y Sociológicas, de la Asociación Nacional de Economistas y Contadores de Cuba y de Flacso Cuba que trabajan en programas vinculados con las cooperativas no agropecuarias ${ }^{4}$.

\section{LA NATURALEZA DE LAS REFORMAS ECONÓMICAS DESDE 2008}

La dinámica económica cubana se ha caracterizado durante más de medio siglo por la recurrencia de ciclos generalmente vinculados con los cambios en su inserción económica internacional o con modificaciones de la misma (Pérez Villanueva, 2009). En particular se deben subrayar aquellos resultantes de su inserción durante tres decenios en el complejo económico conformado por los países socialistas de Europa, primordialmente la Unión Soviética. En esa coyuntura, el colapso de la URSS y la caída de sus aliados socialistas europeos restringieron el acceso de Cuba a los mercados con los cuales había comprometido su desarrollo económico y su comercio, casi desde el triunfo de la revolución (Oliva Campos, 2011), reduciendo marcadamente los intercambios con los países de Europa del Este y perdiendo más del 70\% de su capacidad de compra entre 1989 y 1992 (Castro Ruz F. 1992).

Aunque la caída del campo socialista fue desencadenante de la crisis que sobrevino a comienzos de la década de 1990, sus señales estaban presentes en los años 1986-89 en correspondencia con el estancamiento de su economía. Asimismo, otros aspectos del desempeño económico revelaban problemas provenientes de fallas estructurales de la estrategia de desarrollo, relegados en los primeros treinta años de construcción del socialismo (Triana, 2011). Al respecto se ha planteado que la reinserción del país en un mundo diferente al que conoció en esos años debía realizarse bajo condiciones excepcionalmente difíciles debido a una nueva realidad global (CEPAL, 1997) agravada por el recrudecimiento del embargo norteamericano luego de la aprobación de la Cuban Democracy Act -Ley Torricelli ${ }^{5}$ en 1992 y a la vigencia de la Cuban Liberty and Democratic Solidarity, -Ley Helms-Burton ${ }^{6}$ desde 1996.

Si bien los desafíos que se presentaron a Cuba durante la década del noventa

\footnotetext{
${ }^{4}$ Las entrevistas se aplicaron a tres economistas, dos abogados especializados en Derecho Cooperativo, dos sociólogos, un psicólogo social y un especialista en comunicación.

${ }^{5}$ La ley fue sancionada en el Congreso norteamericano y promulgada por el ex presidente George Bush el 23 de octubre de 1992. Se basó en el proyecto que propone como objetivo "promover una transición pacífica hacia la democracia en Cuba" mediante la "aplicación de presiones apropiadas al gobierno de Cuba y el apoyo al pueblo cubano".

${ }^{6}$ En marzo de 1996 entró en vigencia la Ley de la Libertad Cubana y Solidaridad Democrática, que continuó y reforzó el embargo de Estados Unidos contra Cuba. La ley es conocida por los nombres de sus principales promotores: el senador por Carolina del Norte, Jesse Helms, y el representante por Illinois, Dan Burton.
}

REVESCO No 120 - Primer Cuatrimestre 2016 - ISSN: 1885-8031 - www.ucm.es/info/revesco 
presentaron similitud con los que enfrentó en los años iniciales del proceso revolucionario, en esta nueva coyuntura el país por primera vez debió depender en forma exclusiva de sus propios esfuerzos para establecer, en esas condiciones, una estrategia de supervivencia o emergencia dirigida a minimizar los efectos de la crisis en su población (Pérez Villanueva, 2010). La estrategia, denominada "periodo especial en tiempo de paz", le permitió enfrentar un entorno hostil, único a nivel internacional y las graves condiciones que sobrevinieron luego del peor shock externo que la afectó más que a cualquiera de los miembros del bloque soviético (Morris, 2014). Según Triana (2011) el periodo especial permitió constatar una crisis en la concepción del desarrollo económico y limitaciones en el estilo de crecimiento en Cuba que fueron discutidas en la academia y no en los niveles de decisión.

La profunda crisis económica que condujo a una contracción de hasta $35 \%$ de su PIB entre 1989 y 1993 (Mesa Lago, Pérez-Lopez, 2013, Campbell, 2013) dio lugar al finalizar el periodo especial a la aplicación de un conjunto de reformas económicas parciales que comenzaron con la apertura selectiva de la economía cubana para provocar importantes modificaciones institucionales que generaron nuevas capacidades para una reforma económica más amplia ${ }^{7}$ (Monreal, Rua, 1994).

Ante los desequilibrios y disfuncionamientos macro y microeconómicos la respuesta a la crisis consistió inicialmente (1990-93) en resistir al shock externo, repartiendo al máximo el costo del ajuste y la restricción de la oferta para llegar, en una segunda fase (1993-96), a reactivar las fuerzas productivas ligadas al sector externo, intentando una reinserción en la economía mundial tan rápida y favorable como fuese posible. En una tercera fase que culminó en el año 2000 se trató de conseguir una mejora de la eficiencia a fin de debilitar la restricción externa. Las medidas clave consistieron en dotar a la economía de nuevos motores de crecimiento capaces de transmitirse a la desalentada industria azucarera para generar ingresos en divisas. Las entradas de capital asociadas con el turismo, la inversión extranjera directa y el envío de remesas permitieron reanudar rápidamente el crecimiento. Contrariamente a lo que sucedía en la mayoría de los países europeos del antiguo bloque soviético convertidos al capitalismo, la opción cubana para mantenerse socialista mostró sus frutos: la recuperación económica fue efectiva a fines de 1994 (Herrera, 2005).

En el año 2008, ante el exceso de prohibiciones que pesaban sobre la economía

\footnotetext{
${ }^{7}$ En febrero de 2008 Raúl Castro Ruz fue elegido Presidente del Consejo de Estado de Cuba por los diputados de la Asamblea Nacional del Poder Popular, sucediendo a su hermano Fidel Castro en la presidencia de Cuba a la que había renunciado días antes mediante carta abierta.
}

REVESCO No 120 - Primer Cuatrimestre 2016 - ISSN: 1885-8031 - www.ucm.es/info/revesco 
cubana, fue comunicada por el Presidente de los Consejos de Estado y de Ministros, Raúl Castro Ruz, la intención de eliminar las regulaciones de manera progresiva comenzando por las más sencillas y subrayando que la supresión de otras tomaría más tiempo, debido a las exigencias de un estudio integral y de la realización de cambios en determinadas normativas jurídicas. Al respecto destacó que en algunas de las regulaciones había pesado la influencia de las medidas establecidas contra Cuba por las sucesivas administraciones norteamericanas (Castro Ruz, R. 2008).

En el contexto de administración de la crisis, que se extendió hasta 2010, comenzaron a implementarse reformas de tipo coyuntural (Cuadro 1) entre las cuales las más importantes por su repercusión estuvieron relacionadas con el empleo y la seguridad social. Las medidas adoptadas en materia de empleo fueron congruentes con la necesidad de incrementar la productividad del trabajo $^{8}$ y el logro de eficiencia económica, junto con la impronta de una mayor solidez en la disciplina laboral, prioridades que sobresalieron entre las correspondientes a ese periodo. Las medidas en este ámbito fueron precedidas por el Reglamento General sobre la Organización del Trabajo (Resolución No 26 de 2006) (Mercader Uguina, 2006).

Cuadro 1. Políticas coyunturales, instrumentos e instituciones implicadas 2008-2010

\begin{tabular}{|c|c|c|}
\hline Alcance & Instrumentos & Instituciones de aplicación \\
\hline $\begin{array}{l}\text { Supresión de } \\
\text { controles }\end{array}$ & $\begin{array}{l}\text { - Derogación de prohibiciones y } \\
\text { reglamentaciones que pesaban sobre la } \\
\text { ciudadanía. } \\
\text { - Acceso a servicios (turismo, mercado de } \\
\text { divisas, telefonía) }\end{array}$ & $\begin{array}{l}\text { Ministerio de Comercio Interior } \\
\text { (MINCIN) - Res. No } 43 \text { - } 21 \text {-03- } 2008 \\
\text { Ministerio de la Informática y las } \\
\text { Comunicaciones - Res. No. } 84 \text { - 08-04- } \\
2008\end{array}$ \\
\hline $\begin{array}{l}\text { Regularizació } \\
\text { n deudas del } \\
\text { Estado, }\end{array}$ & $\begin{array}{l}\text { - Pago de deudas a campesinos privados por } \\
\text { parte de la Unión Nacional de Acopio } \\
\text { (UNA) }\end{array}$ & $\begin{array}{l}\text { Ministerio de la Agricultura } \\
\text { Ministerio de Comercio Interior }\end{array}$ \\
\hline
\end{tabular}

\footnotetext{
${ }^{8}$ Cabe destacar que la evolución de la productividad laboral desde 2000 había registrado un crecimiento menor con respecto al ritmo promedio anual de crecimiento del salario $(39,5 \%$ frente al crecimiento de $71,0 \%$ en el salario medio mensual en términos nominales) (Anuario Estadístico de Cuba 2007).

${ }^{9}$ El organismo estatal Unión Nacional de Acopio (UNA) fue creado en 1988 como eslabón entre la producción y la comercialización mayorista (incluyendo las entregas a la industria y la exportación) y la distribución minorista de la que dependían 14 empresas de acopio. La UNA abastecía 378 mercados agrícolas y 1538 placitas proveyendo de alimentos a sectores sociales como educación y salud pública a precios inferiores a los que se compraban las producciones a los agricultores. Entre diciembre de 2004 y fin de 2005 tuvo pérdidas por 58 millones de pesos cubanos y adeudaba a los productores 750 mil pesos cubanos. Esa cifra disminuyó en enero de 2006 a 275 mil pesos cubanos (Forteza, 18-02-2006). En julio de 2014, cuando fueron anunciadas en la Asamblea Nacional del Poder Popular las transformaciones que responderían a los lineamientos del partido fue comunicada su extinción y la de los mercados bajo su administración anunciando que se traspasarían al Ministerio de Comercio Interior (Fonticoba, 4-06-2014). Esas transformaciones coincidieron con los procesos de separación de las funciones empresariales y estatales en 20 organismos de la administración central del Estado, reduciéndose 22.000 cargos y disminuyendo de 102 a 36 las organizaciones de dirección empresarial.
}

REVESCO No 120 - Primer Cuatrimestre 2016 - ISSN: 1885-8031 - www.ucm.es/info/revesco 


\begin{tabular}{|c|c|c|}
\hline $\begin{array}{l}\text { variación } \\
\text { precios } \\
\text { relativos y } \\
\text { desregulación }\end{array}$ & $\begin{array}{l}\text { - Incremento en los precios de carne y leche } \\
\text { pagados al productor por la UNA } \\
\text { - Autorización a los agricultores para la } \\
\text { compra de insumos } \\
\text { - Cambios en el sistema de comercialización } \\
\text { de productos agropecuarios del Ministerio } \\
\text { de la Agricultura } \\
\text { - Redimensionamiento de responsabilidades } \\
\text { de la UNA y empresas involucradas en la } \\
\text { comercialización y distribución de } \\
\text { alimentos agropecuarios }\end{array}$ & \\
\hline $\begin{array}{l}\text { Desregulación } \\
\text { de servicios } \\
\text { de transporte }\end{array}$ & $\begin{array}{l}\text { - Autorización y concesión de licencias } \\
\text { operativas de transporte para privados para } \\
\text { ofrecer servicios a turistas y al público en } \\
\text { general, fijando libremente las tarifas }\end{array}$ & $\begin{array}{l}\text { Ministerio de Transporte -Res. N } \mathrm{N}^{\mathrm{o}} 263 \text { y } \\
\text { normas complementarias - 17-09-2008 }\end{array}$ \\
\hline $\begin{array}{l}\text { Estímulo al } \\
\text { empleo }\end{array}$ & $\begin{array}{l}\text { - Pluriempleo } \\
\text { - Gravámenes sobre las gratificaciones en } \\
\text { pesos convertibles CUC/ o divisas de } \\
\text { empleados de empresas de capital } \\
\text { extranjero } \\
\text { - Pago por resultados } \\
\text { - Eliminación del tope salarial en trabajos en } \\
\text { la producción }\end{array}$ & $\begin{array}{l}\text { Consejo de Estado - Decreto Ley N } \mathrm{N}^{\mathrm{o}} 268 \\
2009 \text { del, que flexibiliza el régimen } \\
\text { laboral del país y legaliza el contrato de } \\
\text { trabajo adicional. } \\
\text { Oficina Nacional de Administración } \\
\text { Tributaria - Res. } 277 \\
\text { Ministerio de Trabajo y Seguridad } \\
\text { Social - Res. } 9 \text { - Reglamento general } \\
\text { sobre las formas y sistemas de pago 02- } \\
02-2008\end{array}$ \\
\hline $\begin{array}{l}\text { Regulación } \\
\text { seguridad } \\
\text { social }\end{array}$ & $\begin{array}{l}\text { - Reforma de pensiones (fijación de edades } \\
\text { de retiro, extensión del periodo de } \\
\text { servicios requerido, aumento y } \\
\text { acumulación de la pensión con el ingreso } \\
\text { por trabajo, cotización según incremento } \\
\text { salarial) }\end{array}$ & $\begin{array}{l}\text { Ministerio de Trabajo y Seguridad } \\
\text { Social - Ley No } 105 \text { de Seguridad Social } \\
\text { - 22-01-2008 }\end{array}$ \\
\hline
\end{tabular}

Fuente: elaboración propia en base a Mesa-Lago 2011, 2012, 2013; Pavel Vidal, 2010 y Gaceta Oficial de la República de Cuba, 2008

En cuanto a la seguridad social se introdujeron significativos cambios en el sistema previsional a partir de la Ley $\mathrm{N}^{\mathrm{0}} 105$ de Seguridad Social adecuándose los requisitos de las pensiones por edad en consonancia con el aumento de la esperanza de vida, al elevar la edad jubilatoria en cinco años y ampliar el tiempo de servicios requerido para otorgarla.

Los instrumentos de la política económica se orientaron al ajuste del gasto físcal tratando de reducirlo a través de la eliminación de "las gratuidades indebidas y el exceso de subsidios" (Castro Ruz, F. 2008). Al respecto fue subrayada la necesidad de una administración estricta de los recursos monetarios puestos a disposición de los organismos, advirtiendo que la capacidad de previsión y la prioridad establecida por sus directivos estaría "permanentemente sometida a prueba". Al respecto se señaló la necesidad de "utilizar solo el recurso de que se dispone, abandonando la nociva práctica que ha imperado en muchas administraciones de realizar el gasto y luego gestionar su financiamiento" (Murillo, 2009). 
Del segundo grupo de reformas de carácter estructural (cuadro 2) cabe destacar como la más significativa la entrega de tierras estatales ociosas en usufructo a cooperativas y productores privados, política que condujo a un nuevo modelo agrícola que enfatizó la participación del sector no-estatal (Nova González, 2012). La redistribución de la tenencia de tierra a favor de este sector fue acompañada además con la introducción de cambios graduales en algunos rubros de la producción agrícola.

Algunas de las reformas tuvieron un alcance limitado ${ }^{10}$ aunque en conjunto tradujeron la importancia y repercusión de los diversos cambios institucionales promovidos en los dos años de presidencia del gobierno de Raúl Castro. Se trata del ámbito donde más acciones concretas fueron adoptadas en correspondencia con la idea de "reforzar la institucionalidad" que se expresó en todos sus discursos (Pavel Vidal, 2010, Rodríguez, 2014). Su importancia radica en que abrieron el paso para un enfoque de transformaciones más radical en el marco del lanzamiento de un debate nacional previo al VI Congreso del PCC que se celebró en abril de 2011.

Cuadro 2. Políticas estructurales e instituciones involucradas 2008-2010

\begin{tabular}{|c|c|c|}
\hline Alcance & Instrumentos & Instituciones implicadas \\
\hline $\begin{array}{l}\text { Reforma sistema } \\
\text { de propiedad de la } \\
\text { tierra estatal }\end{array}$ & $\begin{array}{l}\text { - Autorización de la entrega de tierras } \\
\text { estatales ociosas en concepto de usufructo } \\
\text { a personas naturales o jurídicas por un } \\
\text { término de hasta diez años }\end{array}$ & $\begin{array}{l}\text { Ministerio de la Agricultura } \\
\text { Decreto-Ley } 259-10-07-2008 \\
\text { Decreto No. } 282-27-08-08\end{array}$ \\
\hline $\begin{array}{l}\text { Reforma } \\
\text { administrativa del } \\
\text { sector estatal }\end{array}$ & $\begin{array}{l}\text { - Reducción de plantillas estatales } \\
\text { sobredimensionadas para eliminar de } \\
\text { forma progresiva hasta } 2015 \text { cerca de } \\
500.000 \text { puestos de trabajo (equivalente al } \\
10 \% \text { de la población activa) }{ }^{11} \text {. }\end{array}$ & $\begin{array}{l}\text { Comunicado de la Central de } \\
\text { Trabajadores de Cuba (CTC) } \\
\text { Granma 13-09-2010 }\end{array}$ \\
\hline $\begin{array}{l}\text { Flexibilización } \\
\text { régimen laboral }\end{array}$ & $\begin{array}{l}\text { - Expansión del empleo no estatal para dar } \\
\text { ocupación a los despedidos. } \\
\text { - Estímulo al trabajo por cuenta propia } \\
\text { proyectando un crecimiento del 3\% al } \\
\text { 35\% de la fuerza de trabajo } \\
\text { - Autorización de cooperativas de }\end{array}$ & $\begin{array}{l}\text { Consejo de Estado } \\
\text { Decreto-Ley No } 268 \text { - 26-07-09 } \\
\text { Ministerios de Trab. y Seg. } \\
\text { Social, Finanzas y Precios, } \\
\text { Auditoría y Control, Educ., } \\
\text { Educ. Superior y Salud Pública. }\end{array}$ \\
\hline
\end{tabular}

\footnotetext{
${ }^{10}$ Aunque fueron entregadas en usufructo más de 1.538 .000 hectáreas a 174.000 usufructuarios desde que se adoptó la medida a fines de 2008 , el $16,4 \%$ del total de los 6.342 .000 has que conforman la superficie cultivable de Cuba son tierras ociosas o deficientemente explotadas (ONEI, 2014). El 55\% de estas tierras ociosas (574.000 has) está en manos de empresas agrícolas estatales y un $24 \%$ pertenece a las UBPC. A esto se añade el escaso incremento de la producción agrícola resultante del usufructo, el retraso en la adjudicación del resto de la tierra estatal ociosa y la persistencia de restricciones trabas e inhibiciones que limitaron la efectividad de las medidas adoptadas para resolver los problemas. Se ha subrayado entre ellas la demora que supone poder implementar las medidas mediante leyes aprobadas en la Asamblea Nacional, que se reúne solo en junio y diciembre, o bien por medio de decretos del ejecutivo (Mesa Lago, 2011a).

${ }^{11} \mathrm{El}$ inicio del reajuste se produjo en 2011 en los Ministerios de Industria Azucarera, Agricultura, Construcción, Salud Pública y Turismo en los que fueron suprimidos 140.000 empleos. Junto con las metas físicas se establecieron criterios para asignar el subsidio por despido.
} 


\begin{tabular}{|l|l|l|}
\hline & $\begin{array}{l}\text { producción no agrícola y de servicios en } \\
\text { 222 actividades. } \\
\text { - Legalización del contrato de trabajo } \\
\text { adicional }\end{array}$ & $\begin{array}{l}\text { Resolución No. 32 - 07-09-10 } \\
\text { MTySS Decreto Ley No. 278 - } \\
\text { 30-08-10 }\end{array}$ \\
\hline $\begin{array}{l}\text { Pautas } \\
\text { presupuestarias en } \\
\text { la administración } \\
\text { del Estado }\end{array}$ & $\begin{array}{l}\text { Reducción de gastos de la esfera social. } \\
\text { Sustitución de subsidios de precios para } \\
\text { productos de la libreta de racionamiento } \\
\text { por asistencia a los necesitados. }\end{array}$ & $\begin{array}{l}\text { Asamblea Nacional del Poder } \\
\text { Popular Ley No. 108/10 - } \\
20 / 12 / 09 .\end{array}$ \\
\hline
\end{tabular}

Fuente: elaboración propia en base a Mesa-Lago 2011, 2012, 2013, Pavel Vidal, 2010 y Gaceta Oficial de la República de Cuba, 2008, 2009 y 2010

No obstante la significación de las diversas reformas, persistió para algunos la visión de que el sistema económico vigente no puede servir como punto de partida para el desarrollo. Eso significa que los mecanismos que conducen al desarrollo no pueden operar con efectividad desde la situación actual y al constituir un impedimento plantean la necesidad de transformar ese punto de partida mediante una reforma económica sustantiva que anteceda al resto de los cambios (Monreal González, 2008).

\section{ACERCA DEL DESARROLLO DEL COOPERATIVISMO CUBANO}

Diferentes estudios han señalado el escaso arraigo del cooperativismo en Cuba antes de la revolución de 1959 reconociendo entre los primeros antecedentes el "Programa de Joven Cuba" en la década de 1930 propuesto por Antonio Guiteras Holmes ${ }^{12}$ (Nova González 2011, Barrios 1985, Jiménez Guethón 2003, Pavó Acosta, 2010). El programa planteó como parte de las reformas relacionadas con la cuestión agraria la creación de cooperativas de agricultores y la protección preferente de las mismas, junto con el estímulo a formas mutualistas y cooperativas de crédito.

Posteriormente, la figura cooperativa fue incluida en el texto constitucional de 1940 contemplando su carácter empresarial, en la tradición del constitucionalismo social de la época (Rodríguez Musa, 2012) y considerándola como una alternativa a las empresas tradicionales por su potencialidad para solucionar las dificultades económicas y sociales de la comunidad y como fuente de empleo en función del desarrollo local ${ }^{13}$. Su antecedente fue la experiencia proveniente de las Juntas que desde finales del siglo XIX reunían a campesinos para realizar trabajos y faenas agrícolas en común (Pampín Balado; Trujillo Rodríguez, 1998).

\footnotetext{
${ }^{12}$ Destacado líder político que integró en 1933 el Gabinete de Ministros de Ramón Grau San Martín. Fue fundador en 1934 del movimiento Joven Cuba dirigido a organizar la insurrección frente al gobierno BatistaCaffery-Mendieta (Cabrera, 1974)

${ }^{13}$ El Art. 75 establece que la formación de empresas cooperativas de todo tipo será auspiciada por la ley, la que regulará la definición, constitución y funcionamiento de tales empresas de modo que no sirvan para eludir o adulterar las disposiciones que fija la constitución para el régimen del trabajo (Constitución de la República de Cuba, 1940).
} 
Aunque el texto constitucional declaraba el apoyo que el Estado cubano brindaría para su formación, las cooperativas no llegaron a cobrar importancia y su existencia fue efímera utilizándose por reducidos sectores marginados económicamente y por grupos interesados en su enriquecimiento personal.

No obstante la creación de algunas entidades durante el proceso revolucionario fue solo luego del triunfo de la revolución que se impulsó la creación de cooperativas de productores, consumidores y servicios (Fernández Peiso, 2012) las que surgieron a partir de la promulgación de la Primera Ley de Reforma Agraria en mayo de $1959^{14}$. Esta ley estableció la creación de "cooperativas cañeras" que se crearon a partir de octubre de 1960 recibiendo en usufructo colectivo las tierras expropiadas por el Estado a los latifundistas. Integradas por obreros agrícolas fueron concebidas como un tránsito hacia la granja estatal de modo de resolver el dilema entre nacionalización o reparto de tierras a favor de la estatalización (Arias Guevara, 2006).

En el año 1961 las cooperativas cañeras ocupaban el 8,9\% del fondo agrícola nacional (Figueroa, 1997) aunque su escasa rentabilidad, la falta de autonomía y los bajos niveles de calificación de sus administradores, entre otros factores, las llevaron a una rápida desaparición. Se ha señalado además la inexperiencia y falta de aptitud de sus dirigentes para promover formas de interés directo de los obreros (Rodríguez R.C, 1978). En 1962 se decidió su transformación en granjas cañeras, transfiriendo nuevamente 1.073 .600 hectáreas de propiedad cooperativa a propiedad estatal. Al cumplirse el proceso fundamental de transformación de la propiedad de la tierra en los primeros años de la revolución, se manifestó en amplias zonas rurales la tendencia hacia la organización de formas simples de cooperación, caracterizadas en lo general por la utilización de los beneficios del trabajo colectivo y el mantenimiento de la propiedad individual.

A comienzos de la década del 60 fueron creadas las Cooperativas de Créditos y

\footnotetext{
${ }^{14}$ Por la primera Ley de Reforma Agraria de 1959, considerada la medida revolucionaria más importante en Cuba, se expropió el latifundio, proscribiendo la tenencia extranjera y entregando gratuitamente a campesinos la propiedad de hasta dos caballerías (26,8 hectáreas). Antes de la reforma agraria la tenencia de la tierra se caracterizaba por la existencia de grandes latifundios (1,5\% de los propietarios poseían 2.336 fincas con 4.254.000 has que representaban el $46 \%$ del total nacional) y medianos y pequeños propietarios (199.817 personas ocupaban tierras en concepto de arrendatarios, aparceros, colonos y precarios). Las tierras expropiadas se mantuvieron como proindivisas dada la posibilidad de constituir cooperativas agrarias, favoreciéndose una producción intensiva y tecnificada en gran escala. Como resultado de la aplicación de la ley la propiedad de la tierra quedó estructurada a partir de un sector estatal con 3.903.000 has y un sector privado con 5.174.000 has, representando respectivamente el 44\% y 56 del total (Fernández Reyes, 2013).
} 
Servicios $^{15}$ (CCS) y una década más tarde cooperativas de Producción Agropecuaria (CPA). Con la aprobación de la nueva Constitución de la República de Cuba el 24 de febrero de 1976, estas formas colectivas de propiedad sobre la tierra adquirieron rango jurídico constitucional aunque los requisitos y efectos del acto de integrar las tierras de propiedad individual a la propiedad cooperativa fueron establecidos en 1982 por la Ley $\mathrm{N}^{\mathrm{o}} 36$, de Cooperativas Agropecuarias y su regulación. Esta ley, referida a las cooperativas de producción agropecuaria, las de créditos y servicios y otras modalidades cuyo objetivo coincide con formas superiores de producción del trabajo de los campesinos, rigió el desarrollo del movimiento cooperativo cubano durante veinte años y constituyó el soporte jurídico indispensable para transformar en forma ordenada y voluntaria la pequeña producción campesina individual en formas de producción colectiva (Anteproyecto de ley de cooperativas agropecuarias, Fundamentos, 2000).

Durante los años 90, como parte de las iniciativas promovidas por el Estado durante el periodo especial para hacer más eficiente la agricultura, aplicando fórmulas de incentivo y motivación a los productores a fin de lograr una mayor producción con el menor gasto posible de recursos materiales, se dispuso la creación de Unidades Básicas de Producción Cooperativa (UBPC). Esta nueva forma de organización intentó promover la mejor utilización y conservación de la tierra, de la cual era posesionario el productor, a fin de incrementar en ella la producción de alimentos (Decreto Ley 142, 1993). A estas entidades con personalidad jurídica propia se les concedió el usufructo de la tierra por tiempo indefinido siendo dueñas de la producción y vendiéndola al Estado a través de la empresa o en la forma que éste decidiese. Las UBPC fueron creadas con la expectativa de garantizar un abastecimiento abundante, variado y de calidad de alimentos para la población y llegaron a contar con 3.116.800 hectáreas de las mejores tierras cultivables del país. Sin embargo, la forma organizativa desde su origen presentó distinto tipo de limitaciones (Pérez Rojas, Echevarria 2006). Una evaluación sobre su desempeño en 15 provincias del país reconoció la imposibilidad de recuperación financiera de algunas de ellas. En 2014 un total de 923 UBPC reportaban al cierre de junio de 2014 ganancias de 67.420 .300 pesos cubanos (2.696.812 dólares), mientras que 249 registraban pérdidas superiores a los 10.000.400 dólares (FAO, 2014).

\footnotetext{
${ }^{15}$ Estas cooperativas surgieron al triunfo de la revolución en las zonas tabacaleras de las provincias de Pinar del Río y la antigua Las Villas para dar uso colectivo a los equipos de regadío y las casas de curtir tabaco que fueron propiedad de los latifundistas. Sus integrantes mantuvieron la propiedad individual de sus fincas y demás medios de producción utilizando en beneficio colectivo algunos equipos y maquinarias, así como los sistemas de riego.
}

REVESCO No 120 - Primer Cuatrimestre 2016 - ISSN: 1885-8031 - www.ucm.es/info/revesco 
En 2002, La Asamblea Nacional del Poder Popular, según la propuesta surgida en el IX Congreso de la Asociación Nacional de Agricultores Pequeños, promulgó una nueva legislación cooperativa para propiciar el fortalecimiento y continuo desarrollo de la producción agropecuaria sostenible de las cooperativas y de los pequeños agricultores familiares, como vía importante para contribuir al auge de la economía nacional sancionando la Ley de Cooperativas Agropecuarias y de Créditos Servicios. De acuerdo con dicha ley, la cooperativa de producción agropecuaria (CPA) es una entidad económica que representa una forma avanzada y eficiente de producción socialista con patrimonio y personalidad jurídica propios, constituida con la tierra y otros bienes aportados por los agricultores pequeños, a la cual se integran otras personas, para lograr una producción agropecuaria sostenible (Artíc. 4). Una CCS es definida como la asociación voluntaria de agricultores pequeños que tienen la propiedad o el usufructo de sus respectivas tierras y demás medios de producción, así como sobre la producción que obtienen. Es una forma de cooperación agraria mediante la cual se tramita y viabiliza la asistencia técnica, financiera y material que el Estado brinda para aumentar la producción de los agricultores pequeños y facilitar su comercialización. Tiene personalidad jurídica propia y responde de sus actos con su patrimonio.

En 2014 el conjunto de cooperativas agropecuarias registradas (ONEI, 2014) estaba distribuido de la siguiente forma: 1754 UBPC -cañeras y no cañeras, dedicadas a cultivos varios, cítricos, frutales, café, tabaco y a la ganadería-, 903 CPA y 2504 CCS. Ese año, de las cinco entidades productivas que integran el sector agropecuario (UBPC, CPA, CCS, Privado y Estatal) las cooperativas que mayor eficiencia registraron fueron las CCS (contaban con el $18 \%$ de la superficie agrícola total) y junto con el sector privado participaron en el $74,6 \%$ de la producción de viandas y hortalizas del país. La intervención de las UBPC en la misma producción fue de $6,1 \%$, y la de las CPA de 5,1\%, frente a la participación del Estado que produjo el 14,1\%. Sin embargo, la cantidad de CPA y UBPC y sus membrecías se fueron reduciendo paulatinamente, algunas se desintegraron y no se han creado nuevas (Piñeiro Harnecker, 2012)

La etapa más reciente de desarrollo del cooperativismo en Cuba tiene lugar desde fines del año 2010. A partir del debate sobre el documento de "Lineamientos de la Política Económica y social del Partido y la Revolución"16 -presentado en el VI Congreso del PCC

\footnotetext{
${ }^{16} \mathrm{El}$ debate se desarrolló durante tres meses y participaron cerca de 9 millones de personas en más de 163.000 reuniones realizadas en diferentes organizaciones, registrándose una cifra superior a tres millones de intervenciones. De los lineamientos originales 16 fueron integrados en otros, 94 mantuvieron su redacción, en
}

REVESCO No 120 - Primer Cuatrimestre 2016 - ISSN: 1885-8031 - www.ucm.es/info/revesco 
(2011a) para la "actualización" del modelo socialista- fue enunciado un modelo de gestión económica en el que se incluyeron cinco lineamientos específicos que refieren a las cooperativas.

Basándose en los resultados del debate del programa de política económica se aprobó un conjunto de lineamientos -287 económicos y 26 sociales- que enunciaron soluciones a corto y largo plazo orientadas a garantizar la continuidad e irreversibilidad del socialismo, el desarrollo económico del país y la elevación del nivel de vida de la población en el marco de la necesaria formación de valores éticos y políticos ciudadanos. Las soluciones a corto plazo formuladas en el programa se encaminaron a eliminar el déficit de la balanza de pagos estimulando la generación de ingresos externos y la sustitución de importaciones. Con ellas se esperaba responder a los problemas que de manera inmediata impactaban en la eficiencia económica, la motivación por el trabajo y la distribución del ingreso, creando las condiciones para favorecer el tránsito a una etapa superior del desarrollo. En cuanto a las soluciones de largo plazo se trató de formular medidas para alcanzar la autosuficiencia alimentaria y energética, el uso eficiente del potencial humano y una elevada competitividad en las producciones tradicionales así como el desarrollo de nuevas producciones de bienes y servicios de alto valor agregado (VI Congreso del Partido Comunista de Cuba, 2011a).

Los cambios propuestos suponen una significativa actualización del modelo socialista, calificado también como "socialismo posible". Al respecto se ha subrayado la necesidad de tomar distancia de otras reformas que intentando perfeccionar el socialismo lo llevaron a su desaparición en Europa. En el modelo adoptado "se tiende al perfeccionamiento de la sociedad que se ha construido hasta el presente y se afirman varios rasgos fundamentales que reiteran su matriz socialista" al mantener la propiedad social sobre los medios de producción, determinantes para el desarrollo del país. Asimismo se establecen límites al desenvolvimiento de la propiedad no estatal al reducir su capacidad de acumulación y se asegura la prestación de servicios sociales básicos universal y gratuitamente abriendo espacios a la pequeña propiedad privada, la propiedad cooperativa agropecuaria y no agropecuaria y las empresas

181 se modificó su contenido y se incorporaron 36 nuevos, resultando un total de 311 en el actual proyecto. El documento destaca la orientación a adoptar por la política económica ratificando el principio de que sólo el socialismo es capaz de vencer las dificultades y preservar las conquistas de la revolución para destacar la primacía de la planificación y no del mercado en la actualización del modelo económico. Desde esa perspectiva la planificación centralizada de la economía y el control sistemático que el Estado, el gobierno y sus instituciones deben ejercer, son vistos como garantía del funcionamiento eficiente de los sistemas. Se subraya que estos principios deben ser armonizados con más independencia de las empresas estatales y con el desarrollo de formas de gestión no estatal en la producción y los servicios, para lograr una mayor liberación de las fuerzas productivas, incrementar los niveles de producción y elevar el nivel de vida de la población.

REVESCO No 120 - Primer Cuatrimestre 2016 - ISSN: 1885-8031 - www.ucm.es/info/revesco 
mixtas con capital extranjero. Se parte así del reconocimiento que otras formas de propiedad no estatal pueden contribuir al desarrollo del país, sin ser predominantes aunque se las debe encauzar adecuadamente, es decir, sin que se conviertan en preponderantes. A este cambio significativo se ha llegado reconociendo por un lado, que una propiedad estatal únicamente no asegura el éxito del socialismo en la fase de construcción socialista actual de Cuba y por otro que durante años se trató de seguir ese camino aunque el balance no ha sido favorable ${ }^{17}$ (Rodríguez J.L., 2014a, 2014b)

Desde la perspectiva precedente, el modelo de gestión propuesto en los lineamientos recalcó la necesidad de reconocer y promover la empresa estatal socialista, como forma primordial en la economía nacional, junto con las modalidades de inversión extranjera previstas en la ley (empresas mixtas, contratos de asociación económica internacional, entre otras), las cooperativas, los agricultores pequeños, los usufructuarios, los arrendatarios, los trabajadores por cuenta propia y otras formas, todas las que, en conjunto, debían contribuir a elevar la eficiencia (Lineamiento 2).

Los cinco lineamientos específicos referidos a la creación de cooperativas (25 a 29) destacaron su contribución potencial para aumentar la eficiencia caracterizando estas empresas como una forma socialista de propiedad colectiva en diferentes sectores y organizaciones económicas con personalidad jurídica y patrimonio propio. En la tradición del cooperativismo se destacó el carácter voluntario de la adhesión y su integración por personas que se asocian aportando bienes o trabajo, con la finalidad de producir y prestar servicios útiles a sociedad, asumiendo todos sus gastos con ingresos propios (Lineamiento 25). El enfoque adoptado puntualizó la naturaleza de la cooperativa como forma de propiedad aunque sin enfatizar su particularidad como fenómeno asociativo.

No obstante la contribución del cooperativismo como principal línea de desarrollo en la producción agropecuaria de Cuba y su mayor preparación respecto a la empresa estatal para funcionar bajo rigurosas condiciones de limitación de recursos (Nova González, 2012) cabe

\footnotetext{
${ }^{17}$ Fidel Castro Ruz había expresado en 2010 que "Cuban Model Doesn't Even Work for Us Anymore" (The Atlantic, Sep 8, 2010), mientras que en la búsqueda de argumentos favorables al cambio, quien había sido Ministro de Economía en Cuba hasta 2009, manifestó que "hace ya tiempo que la teoría marxista llegó a la conclusión de que la existencia de relaciones de mercado en el socialismo obedece a un determinado grado de desarrollo en el cual no puede socializarse directamente el trabajo individual de los productores y se requiere de las categorías mercantiles para hacerlo"... se requiere reconocer esa realidad en la medida que se pretende avanzar a un desarrollo más racional (Rodríguez, 2014).
} 
destacar el tardío reconocimiento de las (CNA) aún cuando fuese percibida la necesidad de transformaciones basadas en la realización de la propiedad en diversos escenarios territoriales.

\section{La regulación de las CNA y los procesos constitutivos}

El marco legal ${ }^{18}$ que regula la creación y funcionamiento de las CNA en Cuba se encuentra contenido en los decretos leyes $N^{0} 305$ "De las cooperativas no agropecuarias" y 306 "Del régimen especial de seguridad social de los socios de las cooperativas no agropecuarias" adoptados en noviembre de 2012 por el Consejo de Estado de la República de Cuba, y en el Decreto $N^{0} 309$ del Consejo de Ministros que estableció con carácter experimental el procedimiento para la constitución, registro, funcionamiento y extinción de las CNA de primer grado ${ }^{19}$. De manera complementaria, la resolución № 427 del Ministerio de Finanzas y Precios establece su régimen fiscal y normas contables específicas y la Resolución № 570, del Ministerio de Economía y Planificación regula el procedimiento de licitación de bienes de un establecimiento estatal o una sociedad mercantil para que sean gestionados por las cooperativas.

La nueva forma de gestión no estatal toma en cuenta las diversas experiencias acumuladas por las cooperativas de la rama agropecuaria y establece que las organizaciones pueden ser de primer o de segundo grado. Las de primer grado se conforman mediante la asociación voluntaria de al menos tres personas naturales sustentándose en el trabajo de sus socios. Su objetivo consiste en la producción de bienes y la prestación de servicios mediante la gestión colectiva dirigida a la satisfacción del interés social y el de los socios. Las de segundo grado se integran por dos o más cooperativas de primer grado con el objetivo de organizar actividades complementarias afines o que agreguen valor a los productos y servicios de sus socios, o de realizar compras y ventas conjuntas, con vistas a lograr mayor eficiencia. Cabe señalar que no existen en Cuba experiencias de cooperativas de este tipo ${ }^{20}$.

Debido a que la constitución de las nuevas cooperativas proviene en la mayoría de los

\footnotetext{
${ }^{18}$ El Código Civil vigente desde 1987 en Cuba instituía el reconocimiento jurídico de las cooperativas en su condición de personas jurídicas y como forma de propiedad colectiva para contribuir al desarrollo de la economía nacional, de allí su importancia en el proceso de actualización del modelo económico cubano.

${ }^{19}$ Gaceta Oficial No. 053 Extraordinaria de 11 de diciembre de 2012. Año CX pp 249-253. Recuperado de http://www.fgr.cu/sites/default/files/Decreto\%20Ley\%20305\%20y\%20306.pdf

${ }^{20}$ El escaso conocimiento sobre esta modalidad de asociación en ámbitos urbanos y la distinción entre cooperativas de primer y segundo grado llevó a plantear un número significativo de consultas y pedidos de aclaración en las discusiones previas de los lineamientos. Así el concepto de cooperativas de primer grado se debió aclarar y especificar debido a que suscitó 1130 dudas, del mismo modo que el de cooperativa de segundo grado con 993 dudas (VI Congreso del Partido Comunista de Cuba, 2011b).
} 
casos de procesos inducidos por el Estado con la finalidad de desprenderse de actividades escasamente rentables, demasiado pequeñas o poco productivas, los trabajadores que no están interesados en participar pueden rehusar la incorporación y se les aplica la disposición legal vigente para los trabajadores disponibles. Las atribuciones de los organismos estatales al respecto son de gran amplitud e injerencia ya que además de decidir en qué sectores se conforman y quienes las integrarán, pueden disponer de locales inactivos interesados en contratar a cooperativas a través de un proceso que se realiza por convocatoria pública. Uno de los ámbitos autónomos de su gestión concierne a los precios y tarifas de los productos y servicios a comercializar ya que son determinados por las propias cooperativas en función de la oferta y la demanda, excepto en el caso de las tarifas de transporte público y la venta de alimentos, rubros en que el Estado ejerce control.

En cuanto al régimen fiscal ${ }^{21}$ las cooperativas están gravadas por el impuesto sobre utilidades -de acuerdo con la "utilidad fiscal per cápita" y descontando de los ingresos anuales el mínimo exento por miembro de la cooperativa y los gastos asociados a la actividad-, el impuesto sobre ventas, el impuesto sobre los servicios y el impuesto sobre la utilización de la fuerza de trabajo. En los tres primeros meses desde el inicio de su actividad están eximidas del pago de estas contribuciones.

El proceso administrativo necesario para la constitución de las cooperativas es prolongado y complejo.

Figura 1. Proceso de constitución de las cooperativas

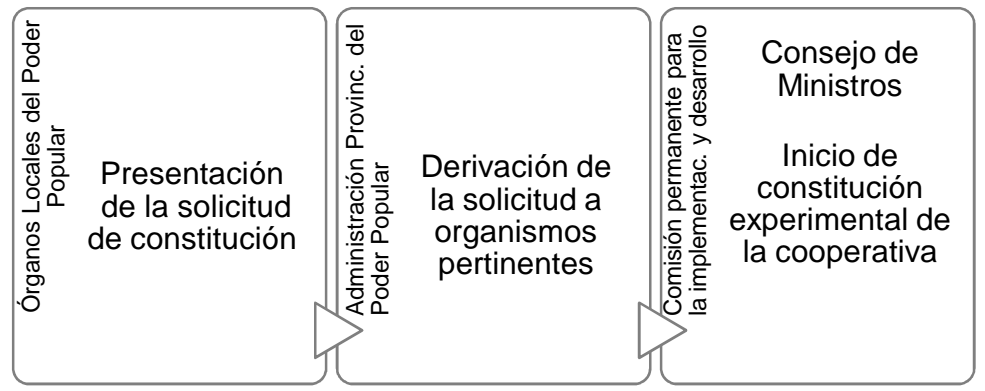

Fuente: elaboración propia en base al reglamento de las CNA de primer grado ${ }^{22}$

El grafico 1 ilustra de manera esquemática los procedimientos necesarios. El inicio coincide con la presentación de la solicitud de constitución ante la dependencia municipal de

\footnotetext{
${ }^{21}$ Contenido en la Ley 113 del Sistema Tributario, con las particularidades que indica la Resolución 427 del Ministerio de Finanzas y Precios.

${ }^{22}$ Decreto No 309 del Consejo de Ministros. Reglamento de las cooperativas no agropecuarias de primer grado. Gaceta Oficial de la República de Cuba. 11 de diciembre de 2012 pp. 260-270.
} 
los órganos locales del poder popular quienes la dirigen a la administración provincial del poder popular para su traslado a los organismos que rigen las actividades que desarrollará la cooperativa. Estos analizan la propuesta y la derivan a la Comisión Permanente para la Implementación y Desarrollo ${ }^{23}$ de donde pasa al Consejo de Ministros. A partir de la aprobación se inicia el proceso de constitución experimental de la cooperativa, constituyéndose como cooperativa en formación. Se designa un socio representante o se crea un "Comité Gestor" en forma conjunta con el órgano local del poder popular, organismo o entidad nacional que corresponda, como responsables del proceso constitutivo. Las organizaciones cuentan con el asesoramiento de la Comisión Permanente para la Implementación y Desarrollo en estas gestiones y la autorización para su constitución es otorgada por un organismo o entidad específico.

Una vez elaborados y aprobados los estatutos la cooperativa se constituye según escritura pública ante notario y el proceso finaliza con la inscripción de la escritura en el Registro Mercantil. Exceptuando los casos en que las gestiones iniciales son realizadas por los organismos estatales que en algunos casos resuelven y facilitan el proceso de conformación, los requerimientos mencionados constituyen un importante desestímulo para los futuros socios y actúan por consiguiente como elementos disuasivos frustrando sus expectativas y limitando sus aspiraciones. La principal limitación radica en que se extiende sobremanera el período de las gestiones de los grupos cooperativos para poder completar los requisitos establecidos, motivo por el cual algunos desisten de constituirse como cooperativa y se organizan como cuentapropistas mientras que otros inician su funcionamiento sin estar constituidas reglamentariamente.

Ninguno de los trámites constitutivos, que incluyen desde la presentación de la solicitud inicial hasta el momento en que se dicta la disposición de autorización, está delimitado temporalmente, ni existen menciones sobre los términos de respuesta por parte de las autoridades. La única referencia a un límite temporal, está dirigida a los aspirantes a socios fundadores, a quienes se les exige un máximo de 60 días una vez dictada la disposición para constituir la cooperativa mediante escritura pública y registrarla (Marín Hita 2014).

\footnotetext{
${ }^{23}$ El Sexto Congreso del PCC al acordar la aprobación de los Lineamientos orientó al Gobierno en la creación de una Comisión Permanente para la Implementación y Desarrollo con la responsabilidad de controlar, verificar y coordinar las acciones de todos los involucrados en esta actividad, proponer la incorporación de nuevos lineamientos y conducir, en coordinación con los órganos competentes, la divulgación adecuada del proceso (VI Congreso del Partido Comunista de Cuba, 2011a).
} 
Desde la vigencia de los decretos que reglamentan la constitución y funcionamiento de las CNA fue autorizado para su funcionamiento entre julio de 2013 y marzo de 2014 un total de 498 cooperativas. Los cuadros 2 y 3 indican las etapas de su evolución y el tipo, localización y origen de las nuevas organizaciones.

El grupo más importante de CNA pertenece al sector de comercio y gastronomía incluye desde restaurantes especializados hasta pequeñas cafeterías barriales-. En 2014 esas cooperativas representaban el $49 \%$ del total de entidades autorizadas. Integradas en su mayoría por empleados de empresas estatales ${ }^{24}$, están orientadas a brindar un servicio de calidad con oferta diversificada que permita garantizar una mayor protección al consumidor. Algunas se constituyeron a partir de la fusión de cafeterías con restaurantes a fin de fortalecer la actividad del servicio en cada lugar. Las regulaciones sobre el sector establecen que se mantiene la propiedad estatal sobre los principales medios de producción mientras que los equipos, medios útiles y herramientas se pueden arrendar o vender. Las cooperativas pueden acceder a los insumos y productos que provee la Empresa Mayorista de Alimentos ${ }^{25}$ con un descuento de entre $15 \%$ y $20 \%$.

El segundo grupo está constituido por las cooperativas comercializadoras de productos agropecuarios (CNAC) y representa el 20\% de las CNA que iniciaron sus actividades en 2013 con el propósito de minimizar la intermediación y lograr una gestión comercial independiente. Estas cooperativas fueron conformadas por decisión estatal en abril de 2013. El Consejo de Ministros autorizó el funcionamiento de 101 entidades y la decisión de integrar su membresía fue comunicada a los trabajadores de los mercados agropecuarios estatales (MAE) sin tomar en cuenta el principio de voluntariedad. En la nueva estructura organizativa conformada, el anterior administrador del MAE se convirtió en presidente de la cooperativa y los puestos de trabajo coincidieron con los que antes desempeñaban sus empleados.

Las cooperativas operan en locales arrendados a la Empresa Provincial de Mercados

\footnotetext{
${ }^{24}$ La red de la gastronomía estatal cuenta con 8.984 instalaciones de todas las categorías. En 2014 representaba un sector con más de 134.000 trabajadores y exceptuando algunos establecimientos fue objeto en las últimas décadas de quejas e insatisfacciones por parte de los usuarios. La mayor parte de los comercios gastronómicos estaba vinculado con el Grupo Empresarial Extrahotelero Palmares S.A, creado en 2004 en el ámbito del Ministerio del Turismo con el propósito de agrupar y desarrollar toda la red extrahotelera e incorporarse al desarrollo del turismo internacional de Cuba.

${ }^{25}$ Hasta inicios de 2013 la comercialización mayorista se realizaba a través de 2400 entidades, de ellas alrededor de 529 empresas eran empresas comercializadoras mayoristas, subordinadas a entidades nacionales. En marzo de 2013, como parte de las reformas económicas, fue creada la Empresa Comercializadora Mayorista de Productos Alimenticios y Otros Bienes de Consumo para comercializar con personas jurídicas y otras formas de gestión no estatales.
}

REVESCO No 120 - Primer Cuatrimestre 2016 - ISSN: 1885-8031 - www.ucm.es/info/revesco 
Agropecuarios de La Habana y a las empresas de comercio y gastronomía de las provincias de Artemisa y Mayabeque. Venden productos agropecuarios con precios de acopio centralizados a precios minoristas máximos, productos con precios de venta minorista centralizados y el resto a precios por acuerdo ${ }^{26}$; asumen todos los gastos por la operación comercial. Adquieren los productos en un mercado mayorista o los compran a un tercero que se los entrega, diferenciándose de los MAE a quienes el Estado aseguraba el abastecimiento. Según la localización y el número de clientes, realizan el aprovisionamiento dos y tres veces en la semana para preservar su calidad, ofrecen por lo general precios inferiores a los de los vendedores ambulantes quienes también recurren a las mismas fuentes de abastecimiento. Aunque el interés manifiesto es brindar productos de buena calidad y precio accesible, el objetivo resulta difícil de alcanzar en algunos casos ya que al precio de compra algunas deben agregar los gastos de transporte por no disponer de movilidad propia, mientras que otras recurren al servicio de la Base Municipal de Transporte que aunque tiene precios justos no dispone de vehículos suficientes ni disponibilidad para circular fuera de una provincia. Algunas cooperativas manifiestan que el alquiler de transporte representa cerca del $60 \%$ de los gastos de operación.

Cuadro 3. Cooperativas no agropecuarias aprobadas por el Consejo de Ministros 2013-2014

\begin{tabular}{|c|c|c|c|c|c|}
\hline Origen & Tipo de cooperativas & $\begin{array}{l}\text { Abril } \\
2013\end{array}$ & $\begin{array}{l}\text { Julio } \\
2013\end{array}$ & $\begin{array}{r}\text { Octub } \\
\text { re } \\
2013 \\
\end{array}$ & $\begin{array}{r}\text { Marzo } \\
2014\end{array}$ \\
\hline \multirow[t]{4}{*}{$\begin{array}{l}\text { Empresas del } \\
\text { Estado }\end{array}$} & $\begin{array}{l}\text { Comercializadoras de } \\
\text { productos agropecuarios }\end{array}$ & 101 & - & - & - \\
\hline & $\begin{array}{l}\text { Servicio transporte de } \\
\text { pasajeros }\end{array}$ & 5 & 2 & 1 & 3 \\
\hline & Reciclaje Desechos & 2 & - & - & - \\
\hline & $\begin{array}{l}\text { Comercio, gastronomía, } \\
\text { servicios }\end{array}$ & - & 22 & 38 & 186 \\
\hline \multirow{2}{*}{$\begin{array}{l}\text { Empresas privadas } \\
\text { y trabajadores por } \\
\text { cuenta propia }\end{array}$} & Construcción & 12 & 12 & 33 & 12 \\
\hline & Servicios contables & - & - & - & 6 \\
\hline \multirow[t]{2}{*}{$\begin{array}{l}\text { Empresas del } \\
\text { Estado y privadas }\end{array}$} & $\begin{array}{l}\text { Servicios auxiliares de la } \\
\text { actividad de transporte }\end{array}$ & 6 & - & - & - \\
\hline & $\begin{array}{l}\text { Industria (prod. reparaciones, } \\
\text { impresiones gráficas, diseño) }\end{array}$ & - & 16 & 1 & 15 \\
\hline
\end{tabular}

\footnotetext{
${ }^{26}$ Según lo establece el Decreto $\mathrm{N}^{\mathrm{o}} 318$ que establece el reglamento sobre la comercialización de productos agropecuarios en las provincias de La Habana, Artemisa y Mayabeque la comercialización de los productos con precios de acopio centralizado a precios minoristas máximos se realiza en los mercados minoristas; las empresas que administran los establecimientos que ocupan los mercados agropecuarios estatales (MAE), aprueban los precios minoristas máximos de los productos agrícolas que se contraten con precios de acopio centralizados; los precios de los productos con precios de venta minorista centralizados son aprobados por el Ministerio de Finanzas y Precios; y el resto de los productos se comercializan de forma minorista a precios por acuerdo.
} 


\begin{tabular}{|l|l|r|r|r|r|}
\hline & Ornitología & - & 17 & - & - \\
\cline { 2 - 6 } & Producción de alimentos & - & 2 & - & 1 \\
\cline { 2 - 6 } & Energía & - & - & - & 5 \\
\hline & Total & 126 & 71 & 73 & 228 \\
\hline
\end{tabular}

Fuente: elaboración propia en base a comunicaciones del Vicepresidente del Consejo de Ministros y datos de la ONEI 2013-2014

La estructura de conformación de este tipo de cooperativas es similar, se limitan a la comercialización y por lo general sus asociados no cultivan ni son alcanzados por la regulación de entrega de tierras en usufructo. Algunas han logrado importantes grados de desarrollo y sus diferencias provienen del nivel de gestión. Establecen los precios de venta según la oferta y la demanda, sin intervención de regulaciones externas en cuanto a su fijación por parte del proveedor o del que comercializa directamente con la población. El margen sobre el precio de venta es de entre $25 \%$ y $30 \%$ y el precio disminuye según la decreciente calidad del producto. Al igual que en los mercados estatales, el precio cambia en función de la calidad aunque existen productos como el arroz, guisantes y carne de cerdo a los que se fijan precios máximos al igual que a los que conforman la dieta médica ${ }^{27}$. En los precios se contempla además la cobertura de los costos de producción que antes asumía la Empresa Provincial de Mercado Agropecuario: arrendamiento del local, transporte, electricidad, agua, gas y telefonía. Algunos de estos servicios se encuentran subsidiados aunque en general su incidencia se traduce en el precio de venta. Algunas cooperativas complementan la actividad comercializadora con la elaboración de dulces para escuelas, centros asistenciales, instalaciones de camping y para brindar a la población.

En cuanto a las cooperativas de construcción (14\% de las autorizadas), su conformación fue estimulada por el Ministerio de la Construcción (MICONS) creando un grupo de trabajo multidisciplinario que impulsó acciones de capacitación y promovió encuentros territoriales dirigidos a los representantes de las 24 cooperativas iniciales con participación de las universidades. Las cooperativas están localizadas mayoritariamente en La Habana (17) y en su mayoría están integradas por entre 30 y 50 asociados (trabajadores por cuenta propia) que adoptan la estructura organizativa del MICONS. Cuentan con equipos integrados por profesionales y trabajadores de oficios de la construcción que adoptan una organización en grupos y brigadas. Cada grupo cuenta con un jefe que controla el desarrollo de las obras y ayuda en su ejecución representando a la cooperativa ante la Junta de

\footnotetext{
${ }^{27}$ El Estado tiene un cupo de pacientes que reciben una dieta y en esos casos las cooperativas las despachan a los consumidores de los comercios cercanos, a los precios que antes establecía el mercado agropecuario estatal.
}

REVESCO No 120 - Primer Cuatrimestre 2016 - ISSN: 1885-8031 - www.ucm.es/info/revesco 
Dirección, principal espacio para la toma de decisiones y para responder a las inquietudes colectivas. En caso de requerir un especialista se lo contrata por tiempo definido. Está conformada por administrativos, jefes de grupos, militantes de la Unión de Jóvenes Comunistas y del Partido Comunista. En algunos casos las cooperativas constituidas asumieron ante las autoridades provinciales el compromiso de trabajar solo en obras estatales durante la primera etapa (el caso de una cooperativa dedicada a reparar los daños ocasionados al sector por el huracán Sandy). Por lo general en el objeto social no se incluye la compra de materiales de construcción dado que esa responsabilidad le corresponde al inversionista de la obra. Las cooperativas cuentan con reglamentos que norman la conducta de los trabajadores en el ámbito laboral y contienen sus deberes y derechos.

Las primeras cooperativas de transporte fueron autorizadas en 2013: dos de taxi rutero (pequeños ómnibus con aire acondicionado y capacidad para 22 pasajeros sentados), una creada a partir de una Base de Transporte Escolar y dos camiones de transporte de pasajeros. Al grupo inicial se agregaron seis. Por el tipo de servicio que brindan, las cooperativas de transporte de pasajeros poseen un encargo estatal que consiste en la continuidad y mejora del servicio que se venía prestando a la población. Están obligadas a mantener el mismo precio aprobado centralmente, las rutas, paradas, horarios y otros atributos del servicio que se definen en la Licencia de Operación del Transporte, previa conformidad de las direcciones territoriales de transporte de los órganos locales del Poder Popular. El monitoreo lo realiza un grupo de trabajo del Ministerio del Transporte quien ha señalado que en los taxis ruteros persiste la tendencia a querer transportar pasajeros de pie mientras que en los camiones, además de transportar más pasajeros de pie de los autorizados, se transportan cargas voluminosas que inciden en la seguridad del vehículo y de los pasajeros. En general esas dificultades ocurrían en el transporte antes de la constitución de las cooperativas. A ello se agrega que la oferta del servicio no satisface la demanda debido a lo limitado del parque automotor, especialmente en los horarios pico.

Las cooperativas continúan gestionando la provisión de los recursos básicos que requieren para su funcionamiento y tratan de mejorar el estado técnico de algunos de los equipos que han heredado de las entidades estatales. Una vez constituidas pueden comprar a empresas comercializadoras e importadoras a precios mayoristas y adquirir el combustible en la red de servicentros estatales mediante tarjeta magnética a precio minorista. El Estado subsidia parte del costo del combustible para garantizar que el precio del pasaje sea de 5 pesos cubanos, monto obligatorio que no puede ser alterado a riesgo de que se le retiren los 
vehículos a la cooperativa. Igualmente, en sus estatutos, establece el sistema de pago a los socios, el cual alcanza el $70 \%$ de las utilidades del año.

Junto con las primeras cooperativas de transporte se crearon seis cooperativas de servicios auxiliares y conexos como talleres de chapistería, pintura y tapicería, dos antiguos servicentros en los que se prestan servicios de mecánica, neumáticos, lavadero, etc. y servicio de grúa de auxilio en carretera.

Las cooperativas industriales son poco numerosas y desarrollan estrategias escasamente diversificadas. Predominan los talleres de confección textil y de materiales de construcción. En el grupo sobresale por su trayectoria una iniciativa establecida en Varadero a partir de un pequeño grupo de trabajo especializado desde 1996 en la producción y comercialización de impresiones gráficas y la ejecución de proyectos de diseño gráfico, industrial y urbanístico. La cooperativa se inició con cinco socios y espera ampliar la participación hasta 12. Uno de sus proyectos en desarrollo está dirigido al Grupo Empresarial Correos de Cuba para personalizar los puntos de ventas que tiene en los hoteles del país. También prevé la renovación y el mejoramiento de la imagen corporativa de unos 400 quioscos de ventas pertenecientes a la empresa de correos. Esta cooperativa contribuye además con el desarrollo de varios proyectos en beneficio de la comunidad, hogares de menores, escuelas etc. Entre otras iniciativas autorizadas se encuentran 17 cooperativas de ornitología, dos de producción de alimentos 2 de reciclado y 5 de energía.

Aunque las variantes de conformación de CNA son diversas ${ }^{28}$, la casi totalidad se ha constituido a partir del arrendamiento de medios de producción del patrimonio estatal (como los inmuebles y otros activos fijos). Dado que no todas tienen acceso a un mercado mayorista de suministros, en las que surgen de establecimientos estatales en que se modifica la forma de gestión, el Estado continúa proveyendo el abastecimiento a precios mayoristas o minoristas con los descuentos establecidos y en las mismas cantidades que brindaba hasta el momento de cambiar su condición. En caso de incrementarse sus niveles de actividad y requerir más insumos pueden acceder a los mercados junto con el resto de las formas no estatales que coexisten en la economía.

\footnotetext{
${ }^{28}$ Dichas variantes incluyen las basadas en los aportes de sus socios para conformar un patrimonio colectivo; la unión de socios que conservan la propiedad de sus bienes con la finalidad de adquirir conjuntamente insumos y servicios, u otros; el arrendamiento de medios de producción del patrimonio estatal (como los inmuebles y otros activos fijos) o la combinación de las opciones anteriores.
} 
Cuadro 4. Cooperativas no agropecuarias según objeto y localización (2014)

\begin{tabular}{|c|c|}
\hline $\begin{array}{l}\text { Tipo de } \\
\text { cooperativas y } \\
\text { número }\end{array}$ & Objeto y localización \\
\hline $\begin{array}{l}\text { Comercializadora } \\
\text { s de productos } \\
\text { agropecuarios } \\
(101)\end{array}$ & $\begin{array}{l}\text {-Descentralización de la comercialización de productos agrícolas. } \\
\text { - Actúan en el mismo espacio de mercado que los puntos de venta, trabajadores por } \\
\text { cuenta propia, vendedores minoristas, cooperativas agrícolas que arriendan espacios } \\
\text { urbanos de venta y un reducido número de mercados agropecuarios estatales. Fueron } \\
\text { conformadas por empleados de los mercados agropecuarios estatales que hasta } 2013 \\
\text { eran abastecidos por la Unión Nacional de Acopio. } \\
\text {-Su provisión depende de compras de productos en el mercado mayorista o a un tercero. } \\
\text { No reciben subsidios y sus precios se establecen por la relación de oferta y demanda. } \\
\text {-Localizadas en La Habana, Mayabeque y Artemisa }\end{array}$ \\
\hline $\begin{array}{l}\text { Servicio de } \\
\text { transporte de } \\
\text { pasajeros (11) }\end{array}$ & $\begin{array}{l}\text {-Prestación de servicios de transporte de pasajeros y de carga. } \\
\text {-Según la naturaleza del servicio pueden tener o no un encargo estatal. En el caso del } \\
\text { transporte de pasajeros, la cooperativa está obligada a prestar servicios por interés del } \\
\text { Estado en función pública bajo las condiciones preestablecidas de precio, rutas, paradas } \\
\text { y horarios que fija la Licencia de Operación de Transporte, previa aprobación de las } \\
\text { direcciones territoriales de transporte de los órganos locales del Poder Popular. } \\
\text {-Localizadas en La Habana, Mayabeque y Artemisa. }\end{array}$ \\
\hline $\begin{array}{l}\text { Reciclaje de } \\
\text { desechos (2) }\end{array}$ & $\begin{array}{l}\text { - Recuperación, procesamiento y comercialización de materiales y desechos reciclables } \\
\text { que se generan en la industria, los servicios y la comunidad. } \\
\text {-Constituidas por trabajadores de la Unión de Empresas de Recuperación de Materias } \\
\text { Primas perteneciente al Ministerio de la Industria Sideromecánica. La empresa asignó } \\
\text { un anticipo para su creación lo que permitió constituir un fondo operativo con efectivo } \\
\text { disponible para } 30 \text { días de compra. Cuentan con vehículos para la carga que permiten la } \\
\text { búsqueda o gestión de insumos en las empresas estatales o la compra directa a la } \\
\text { población. Se abastecen además de productos reciclables que la población lleva al local } \\
\text { de la cooperativa motivado por la forma de pago en efectivo, en lugar del cheque que } \\
\text { brindaba la empresa estatal. } \\
\text {-Localizadas en Artemisa y Mayabeque }\end{array}$ \\
\hline $\begin{array}{l}\text { Comercio, } \\
\text { gastronomía, } \\
\text { servicios (246) }\end{array}$ & $\begin{array}{l}\text { - Oferta de servicios de calidad incorporando buenas prácticas y haciéndolos sostenibles } \\
\text { en el tiempo. En el caso de restaurantes mantener como mínimo tres ofertas ajustadas } \\
\text { al poder adquisitivo de un segmento importante de los consumidores, reflejando } \\
\text { además la voluntad de proteger a los ciudadanos. } \\
\text {-La irrupción de pequeños comercios gastronómicos en manos de cuentapropistas desde } \\
2008 \text { representó una fuerte competencia para las empresas estatales del rubro y puso en } \\
\text { evidencia el retroceso de numerosos locales que vieron una caída progresiva de sus } \\
\text { ventas. La escasa calidad y variedad de los productos e insumos, la falta de } \\
\text { mantenimiento de los locales y las limitaciones del personal para la atención al público } \\
\text { llevaron al Estado a desprenderse progresivamente de sus establecimientos como } \\
\text { también a concesionar a las cooperativas y cuentapropistas varios servicios que brindan } \\
\text { las empresas estatales responsables de promover la recreación y el esparcimiento entre } \\
\text { la población. } \\
\text {-Localizadas en todas las provincias y mayoritariamente en la Habana, Artemisa, Pinar } \\
\text { del Rio y Matanzas. }\end{array}$ \\
\hline Construcción (69) & $\begin{array}{l}\text {-Construcción de toda clase de obras públicas y privadas, producción de materiales y } \\
\text { prestación de servicios en orden a la conservación y mantenimiento de obras edificios } \\
\text { destinados a fines industriales, comerciales o de vivienda. Utilizan materiales de obras } \\
\text { que facilita el inversionista y no el constructor. } \\
\text {-Radicadas en todas las provincias }\end{array}$ \\
\hline $\begin{array}{l}\text { Servicios } \\
\text { contables (2) }\end{array}$ & $\begin{array}{l}\text {-Oferta de servicios de gestión del proceso organizativo, administrativo y económico } \\
\text { financiero a las entidades que lo soliciten. Solución y mejoramiento en la prestación de } \\
\text { la asistencia profesional de servicios contables y asistencia técnica para la creación, } \\
\text { asociación, extinción y/o liquidación de entidades; facilitación, tramitación y } \\
\text { diligencias económico financieras, tributarias y administrativas para personas jurídicas }\end{array}$ \\
\hline
\end{tabular}




\begin{tabular}{|c|c|}
\hline & $\begin{array}{l}\text { y naturales. } \\
\text {-Radicadas en la Ciudad de La Habana y Villa Clara }\end{array}$ \\
\hline $\begin{array}{l}\text { Servicios } \\
\text { auxiliares } \\
\text { actividad de } \\
\text { transporte (6) }\end{array}$ & $\begin{array}{l}\text {-Prestación de servicios auxiliares o conexos al transporte (un taller de chapistería, } \\
\text { pintura y tapicería, dos antiguos servicentros de servicios de mecánica, gomería, } \\
\text { fregado, etc., una planta de fregado, una gomería y una de servicio de grúa de auxilio } \\
\text { en carretera). } \\
\text {-Localizadas en la Habana }\end{array}$ \\
\hline Industria (32) & $\begin{array}{l}\text {-Transformación de materias primas en productos manufacturados, productos } \\
\text { elaborados o productos terminados para su distribución y consumo. Incluye } \\
\text { cooperativas de confecciones textiles, de producción de calzado y gráficas. } \\
\text {-Localizadas en la Habana, Artemisa y Mayabeque }\end{array}$ \\
\hline Ornitología (17) & $\begin{array}{l}\text {-Cría de aves ornamentales en cautiverio, adquisición, producción y venta de aves, } \\
\text { alimentos, jaulas, insumos, medicamentos, literatura especializada y accesorios } \\
\text { necesarios para el desarrollo de la actividad. Existe una cooperativa en cada provincia y } \\
\text { una en la Isla de la Juventud además del ente importador/exportador }\end{array}$ \\
\hline $\begin{array}{l}\text { Producción } \\
\text { alimentos (2) }\end{array}$ & $\begin{array}{l}\text { - Desarrollar procesos relacionados con la cadena alimentaria. El sector incluye una } \\
\text { cooperativa dedicada a la conservación de alimentos (especias) y otra a la industria de } \\
\text { las bebidas (producción de vinos). } \\
\text {-Localizadas en la Habana }\end{array}$ \\
\hline Energía (5) & $\begin{array}{l}\text { - Promover la diversificación de la matriz energética basándose en combustibles que } \\
\text { resulten sustentables, tanto económica como medioambientalmente. Su objeto es la } \\
\text { producción energética a partir de fuentes renovables de energías y ofrecer servicios } \\
\text { especializados asociados a la actividad. } \\
\text {-Localizadas en la provincia de La Habana. }\end{array}$ \\
\hline
\end{tabular}

Fuente: elaboración propia en base a: entrevistas a funcionarios e investigadores, visitas a cooperativas (noviembre de 2014) y notas en periódicos nacionales y locales

Las cooperativas tienen acceso a todos los servicios bancarios, con vistas a facilitar sus transacciones financieras. El vínculo con las entidades bancarias fue el que más dificultades presentó en el momento de constitución de las primeras cooperativas, debido a falta de información y desconocimiento tanto por parte del personal del banco como de los futuros socios.

\section{POTENCIALIDAD Y LIMITACIONES ORGANIZACIONALES DE LAS COOPERATIVAS NO AGROPECUARIAS}

El importante potencial de recursos que movilizan las cooperativas y el renovado interés por su contribución a los procesos de desarrollo territorial es tributario del interés y la riqueza de las prácticas y relaciones de colaboración entre los actores que las constituyen. La literatura sobre las cooperativas ha puesto de manifiesto esta vinculación y sus efectos positivos en el trabajo y la vida de la organización, en especial en el campo del cooperativismo de producción y de trabajo (Rothschild 2009, Fairbairn 2005, Defourny 1986, Razeto Migliaro 1982, Sanchez Bajo, Roelants 2011).

El caso de las nuevas cooperativas en Cuba puede establecerse sobre estas premisas. A ello se debe añadir también el papel que pueden asumir las organizaciones creadas como 
herramienta para evaluar los compromisos y responsabilidades que le corresponden al Estado al haberlas promovido. Aunque la novedad de estos procesos y su corta vida impiden esbozar apreciaciones generales, es indudable que el aprendizaje organizacional que permitió poner en marcha las experiencias pudo facilitar en general la toma de decisiones y producir algunas de las transformaciones requeridas. Queda por conocer hasta qué punto esta nueva configuración estructural y cultural puede favorecer la cooperación, la innovación, la flexibilidad y la mejora, promoviendo con mayor intensidad la participación de sus integrantes y otorgándoles un mayor protagonismo e implicación en su condición de socios-trabajadores. En este aspecto está en juego la potencialidad de la fórmula cooperativa y su capacidad para revertir las prácticas laborales conformadas a partir de la naturaleza burocrática y jerárquica de las empresas estatales en las que se desarrollaron sus miembros.

Sobre estas apreciaciones es importante mencionar las limitaciones presentes desde su origen que pueden condicionar la evolución de las organizaciones. En primer lugar y desde la instancia constitutiva se debe señalar el peso y la complejidad de las regulaciones y las decisiones que no siempre provienen de los actores involucrados. A ello se agregan los medios limitados que impiden una diversificación de los productos, los insuficientes ingresos para financiar sus obligaciones, el límite en el número inicial de miembros, los problemas de falta de insumos y acceso a los mercados mayoristas etc. ${ }^{29}$

Al igual que otras iniciativas empresariales, la cooperativa constituye el fruto de acciones y de voluntades. Su puesta en marcha y crecimiento posterior no van de suyo y aunque están marcadas por la impronta de haber sido inducidas, su desarrollo no tiene un carácter espontáneo sino que resulta de múltiples decisiones por parte de sus miembros: la de incorporarse o no, la de organizar la producción en respuesta a la demanda, o la de sostener con mayores esfuerzos la actividad cotidiana, entre otras. En este caso la potencialidad puede asumir diversas intensidades, según la calidad y ambición de sus integrantes y en particular de sus dirigentes evitando el sesgo de control sobre el crecimiento posible de la nueva organización por considerarlo como un riesgo.

\footnotetext{
${ }^{29}$ Algunas de las limitaciones comunes a las nuevas experiencias fueron identificadas a partir de acciones de control realizadas por los parlamentarios durante el primer semestre del 2014 identificándose como problemáticas las relaciones económico-financieras y de contratación entre las entidades estatales y las cooperativas, el establecimiento de exigencias no previstas en las normas jurídicas, limitaciones para acceder a la compra de insumos mayoristas y el desconocimiento general sobre el tema. Asimismo otras limitaciones fueron consignadas en el Reporte de investigación de cooperativas no agropecuarias (Hernández Delis et al. 2014).
}

REVESCO No 120 - Primer Cuatrimestre 2016 - ISSN: 1885-8031 - www.ucm.es/info/revesco 


\section{Acerca de la membresía}

En términos del futuro y potencialidad de este tipo de cooperativas y desde la perspectiva de sus miembros los procesos de desarrollo suponen en general la reconstrucción de una nueva identidad, conforme a una condición distinta como trabajador. Se trata en este caso de la condición de "emprendedor", en un marco colectivo o cooperativo, y de copropietario de una organización que debe ofrecer bienes o servicios de una demanda en un contexto de fuerte regulación y de no propiedad de algunos bienes. Un tipo de estructura que facilita la multiplicación de contactos directos y personales así como un estilo de gestión fuertemente orientado hacia las tareas y personas puede resultar en una mejor integración, que a la vez conduzca a una valorización personal de sus miembros.

Estos aspectos suponen atravesar un proceso progresivo de aceptación de la condición de cooperador/a y el requerimiento de mayores responsabilidades y nuevos y más amplios compromisos. La posibilidad del asociado de compararse con otros trabajadores, con la empresa estatal anterior, con cuentapropistas, o con microempresarios privados y confrontar su posición con la situación y condiciones previas es inevitable cuando se indaga por el grado de satisfacción con el trabajo y con la organización. Es recurrente referir a que se gana más que en el trabajo anterior, que se puede acceder a mayores beneficios personales ahora, y que se trabaja más intensamente y mejor. Al respecto se reconoce por un lado una diferencia marcada en cuanto a la seguridad del empleo anterior y por otro se subraya que es necesario un mayor esfuerzo y existen mayores exigencias si se toman en cuenta los requerimientos de los otros (en especial los clientes) respecto a la calidad del trabajo de la cooperativa.

Resulta innegable la exigencia de mayor responsabilidad y compromiso que esta modalidad supone para asegurar la estabilidad económica presente y futura en la medida que no se puede volver al Estado como empleador. El principal desafío se encuentra entonces en un mercado de trabajo y de bienes y servicios con todos los riesgos e incertidumbres que normalmente trae asociado.

Punto inicial de una carrera para algunos, ruptura de la continuidad para otros, la nueva situación se contrapone con la antigua visión que tenían los trabajadores de su futuro. El esfuerzo colectivo de inserción en un ámbito de trabajo que debe ser adaptado a esa nueva condición constituye en general un factor favorable en el proceso de reconstrucción de la identidad. En dicho proceso puede resultar clave el apoyo profesional y los vínculos con 
experiencias similares que ayuden a sostener la estabilidad económica presente y futura en un mercado de trabajo que no presentará las mismas exigencias que en el pasado.

\section{CONCLUSIONES}

En el marco de las reformas económicas iniciadas en 2008 en Cuba, la promoción de la etapa experimental de desarrollo de las CNA representa un hecho novedoso, basado en el reconocimiento del importante potencial de recursos que movilizan estas organizaciones y el renovado interés por su contribución a los procesos de desarrollo territorial.

El análisis ha mostrado que las decisiones adoptadas por el Estado en cuanto a su reconocimiento e impulso se produjeron en consonancia con las transformaciones económicas introducidas en el modelo de gestión económica y que estas organizaciones no siempre se han constituido por voluntad de sus socios.

Su importancia radica en la transformación que puede producirse en las prácticas colectivas modeladas originalmente en un contexto y en condiciones laborales dependientes del Estado. A esto se agrega la particularidad de cooperativas en las que sus miembros no aportan capital ni medios para conformarlas y el Estado continúa siendo propietario de los bienes, aunque en su funcionamiento no se subordinen administrativamente a ninguna entidad estatal y los órganos municipales no ejerzan sobre ellas funciones administrativas.

Aunque la potencialidad de estas cooperativas reside en haber favorecido la diversificación de opciones para generar empleo e ingresos, buscando en algunos casos mejorar la calificación y responsabilidad de los trabajadores, son numerosas las limitaciones que pesan sobre su desarrollo autónomo.

En particular se destaca el involucramiento estatal tanto en la fase constitutiva de las entidades como en el otorgamiento de personalidad jurídica y la fijación del objeto social, en las instancias de aprobación de los planes productivos y la supervisión de su cumplimiento y en la imposición de una carga tributaria que, aunque resulte menos gravosa que para el trabajo por cuenta propia, puede convertir al Estado en uno de los principales beneficiarios de la actividad económica de las cooperativas.

Algunos de los aspectos relevantes de estos procesos han sido apenas enunciados en el marco de este análisis intentando mostrar que las experiencias en el campo del cooperativismo en Cuba se pueden transformar ya que, por lo general, no son lineales ni 
tampoco irreversibles.

A partir de estas observaciones numerosos temas de investigación pueden ser objeto de desarrollo y posibilitar una comprensión amplia sobre los mecanismos múltiples y complejos que operan en todo proceso de transformación organizacional. Al respecto resultaría de interés apreciar las diferencias en la gestión de aquéllas cooperativas constituidas a partir de la decisión de una empresa estatal de cooperativizar las unidades empresariales y requerir posteriormente el acuerdo de los trabajadores concernidos, de la propia de las iniciativas que se han conformado de manera independiente de los organismos estatales. Asimismo una mayor atención a los mecanismos que conducen a la búsqueda de equilibrio entre la gestión empresarial y la asociativa permitiría considerar la sustentabilidad de la cooperativa en la dimensión social, centrándose en particular en las relaciones asociativas.

Desde esta perspectiva, los interrogantes consisten en conocer hasta que punto las cooperativas cubanas que han surgido de las reformas recientes y aquellas que se creen en el futuro podrán sustraerse del impacto de contextos anteriores que puedan determinar el camino a adoptar, o bien en qué medida y bajo qué condiciones será posible consolidar estrategias diseñadas por los propios cooperadores que tiendan a fortalecer los principios de adhesión voluntaria y autonomía en que se fundan las cooperativas.

\section{BIBLIOGRAFÍA}

ALIANZA NACIONAL DE AGRICULTORES INDEPENDIENTES DE CUBA (ANAIC) (2000) Anteproyecto de Ley de las Cooperativas Agropecuarias. Fundamentos.

ARIAS GUEVARA M. A. (2006) Cuba: La crisis de los noventa y el tránsito hacia un nuevo modelo tecnológico en la agricultura. En Desenvolvimento e Meio Ambiente, nº 14, pp. 2331.

BARRIOS A.M. (1985) Historia política de los campesinos cubanos. En P. González Casanova (coord.). Historia política de los campesinos latinoamericanos, pp.41-54. España: Siglo XXI Editores.

CABRERA O. (1974) Antonio Guiteras su pensamiento revolucionario, La Habana, Ciencias Sociales.

CAMPBELL A. (2013) Cuban Economists on the Cuban Economy. Gainesville, FL: The University Press of Florida. 
CASTRO RUZ F. (1992) Discurso pronunciado el 5 de septiembre de 1992. Recuperado de http://www.cuba.cu/gobierno/discursos/1992/esp/f050992e.html.

CASTRO RUZ R. (2008) Discurso pronunciado en el Segundo Período de Sesiones de la VII Legislatura de la Asamblea Nacional del Poder Popular, en el Palacio de Convenciones, el 27 de diciembre de 2008. Recuperado de:

http://www.cuba.cu/gobierno/rauldiscursos/2008/esp/r271208e.html.

CASTRO RUZ R. (2008) Discurso pronunciado como Presidente de los Consejos de Estado y de Ministros en las conclusiones de la Sesión Constitutiva de la VII Legislatura de la Asamblea Nacional del Poder Popular 24 de febrero de 2008. Recuperado de http://www.cuba.cu/gobierno/rauldiscursos/index2.html.

CASTRO RUZ R. (2011) Informe Central al VI Congreso del Partido Comunista de Cuba La Habana 16.04.2011

http://www.latinreporters.com/cubaRaulCastroPCCInforme16042011.pdf.

CEPAL (1997) La economía cubana: reformas estructurales y desempeño en los noventa (Nota informativa resumen). Recuperado de http://repositorio.cepal.org/bitstream/handle/11362/34351/S9700604_es.pdf?sequence=1.

DEFOURNY J. (ed.) (1986) The Economic Performance of Self-Managed Firms. A Comparative Perspective. Special Issue of the Annals of Public and Cooperative Economics, vol. 57/1, 3,9.

FAIRBAIRN B. (2005) Tres Conceptos estratégicos para la orientación de cooperativas. Vínculos, transparencia y cognición. En Documento 48, Centro de Estudios de Sociología del Trabajo. Recuperado de http://www.econ.uba.ar/cesot/docs/documento\%2048.pdf.

FAO (2014, 4 de diciembre) Cuba disuelve cooperativas agrícolas ineficientes. En AgroNoticias América Latina y el Caribe. Recuperado de http://www.fao.org/agronoticias/agro-noticias/detalle/es/c/271086/.

FERNÁNDEZ PEISO A. (2012) La cooperativa. Bases para su legislación en Cuba, La Habana: Editorial de Ciencias Sociales.

FERNÁNDEZ REYES G.D. (2013 14 mayo) La verdadera historia de la Reforma Agraria en Cuba: se cumple el compromiso de la revolución democrática. [Mensaje en un blog] Recuperado de http://cubacid.blogspot.com.ar/2013/05/la-verdadera-historia-de-la-reforma.html.

FIGUEROA V. (1997) La Reforma económica en la agricultura cubana. (Tesis Doctoral) Universidad de La Habana, Cuba. 
FONTICOBA O. (2014, 4 de julio) Agricultura: aciertos y dificultades. Granma. Recuperado de http://www.granma.cu/cuba/2014-07-04/agricultura-aciertos-y-dificultades.

FORTEZA F. (2006, 18 de febrero) Cuba: siguen análisis sobre comercio de alimentos agrícolas. World Data Service. Recuperado de http://www.profesionalespcm.org/_php/MuestraArticulo2.php?id=5511.

HERNÁNDEZ DELIS M., PÉREZ D.S, GAINZA G., REINOSO GUTIÉRREZ O., PADRÓN SÁNCHEZ N., PIÑEIRO HARNECKER C. y OJEDA SURÍS D. (2014) Reporte de investigación de cooperativas no agropecuarias (manuscrito inédito).

HERRERA R. (2005) Réflexions sur l'économie cubaine. En Cahiers de la Maison des Sciences Economiques. p.68. <halshs-00196369>.

JIMÉNEZ GUETHÓN R. (2003) El cooperativismo cubano: historia, presente y perspectivas. En Revista UniRcoop, Red Universitaria de las Américas en estudios Cooperativos y Asociativismo, 1/2.

MARÍN HITA L. (2014) Las cooperativas no agropecuarias en Cuba. REVESCO. Revista de Estudios Cooperativos, no 115, pp. 132-158. DOI:10.5209/rev_REVE.2014.v114.44294.

MERCADER UGUINA J. (2006) Recientes reformas en la normativa laboral en Cuba. Actualización del libro La realidad laboral en Cuba y la responsabilidad social de los inversores extranjeros, Valencia, Tirant lo Blanch. Recuperado de http://www.cubastudygroup.org/index.cfm/files/serve?File id=93124c46-91a7-405a8a7b-bfbb6b622e04.

MESA-LAGO C. (2011a) Cuba: ¿qué cambia tras el VI Congreso del Partido Comunista. En Espacio Laical 3/2011, pp. 27-33. Recuperado de http://www.espaciolaical.org/contens/27/2733.pdf.

MESA-LAGO C., PÉREZ-LÓPEZ, J. (2013) Cuba's Economic and Social Development, 1959-2012. En C.Mesa Lago, J. Pérez-López Cuba Under Raúl Castro: Assessing the Reforms, pp 1-25. Boulder CO: Lynn Rienner.

MESA-LAGO, C. (2011) Las reformas de Raúl Castro y el congreso del Partido Comunista de Cuba: avances, obstáculos y resultados. Documentos Cidob América Latina 35. Centre for International Affairs. Barcelona.

MESA-LAGO C. (2012) Cuba en la era de Raúl Castro: Reformas económico-sociales y sus efectos., Madrid: Editorial Colibrí.

MESA-LAGO C. (2013) Los cambios en la propiedad en las reformas económicas estructurales de Cuba. En Espacio Laical Suplemento Digital, 223. Recuperado de http://espaciolaical.org/contens/esp/sd_223.pdf. 
MONREAL GONZALEZ P. (2008) El problema económico de Cuba. En Espacio Laical 2, 203-206. Recuperado de http://www.cubaencuentro.com/var/cubaencuentro.com/storage/original/application/bef2f 2ef389dd5544143a2f59dcce15e.pdf.

MONREAL P. (1991) Cuba y la nueva economía mundial: el reto de la inserción en América Latina y el Caribe. Working Paper \#157. Kellogg Institute. Recuperado de https://kellogg.nd.edu/publications/workingpapers/WPS/157.pdf.

MONREAL P., RUA M. (1994) Apertura y reforma de la economía cubana: las transformaciones institucionales (1990-1993) En Estudios Internacionales. 27/107-108, pp. 542-569.

MORRIS E. (2014) Cuba inesperada. En New Left Review, no 88, pp. 7-51. Recuperado de http://editorial.iaen.edu.ec/wp-content/uploads/2014/12/NLR_88_ecuador.pdf.

MURILlO M. (2009) Presentación del Vicepresidente del Consejo de Ministros y Ministro de Economía y Planificación del Informe sobre los resultados económicos de 2009 y los Lineamientos del Plan Económico y Social y del Presupuesto del Estado para 2010. Recuperado de http://www.eleconomista.cubaweb.cu/2009/nro371/discurso-marino.html.

NOVA GONZÁLEZ A. (2011) Las cooperativas y la construcción socialista en Cuba. Las cooperativas agropecuarias en Cuba: 1959-presente. En C. Piñeiro Harnecker (comp.) Cooperativas y socialismo: una mirada desde Cuba, pp. 321. La Habana: Editorial Caminos.

NOVA GONZÁLEZ A. (2012, 05 de Marzo) La economía cubana a las puertas de un nuevo cooperativismo. IPS-Inter Press Service. Recuperado de http://www.ipscuba.net/index.php?option=com_k2\&view=item\&id=3507:laeconom\%C3\%ADa-cubana-a-las-puertas-de-un-nuevo-cooperativismo\&Itemid=10.

OFICINA NACIONAL DE ESTADÍSTICA E INFORMACIÓN (2007) Anuario Estadístico de Cuba 2007.

OFICINA NACIONAL DE ESTADÍSTICA E INFORMACIÓN (2014) Panorama Uso de la Tierra Cuba 2013.

OFICINA NACIONAL DE ESTADÍSTICA E INFORMACIÓN (2015) Sector agropecuario. Indicadores Seleccionados. Enero - Diciembre de 2014.

OFICINA NACIONAL DE ESTADÍSTICA E INFORMACIÓN (2015) Organización Institucional. Principales entidades. Enero - Diciembre 2014.

OLIVA CAMPOS C. (2011) Las relaciones de Cuba con América Latina y el Caribe: Imperativos para consolidar la reinserción regional. En L.F. Ayerbe (coord.) Cuba, 
Estados Unidos y América Latina frente a los desafíos hemisféricos, pp. 81-84. Icaria Editorial, Instituto de Estudos Econômicos e Internacionais Coordinadora Regional de Investigaciones Económicas y Sociales.

PAMPÍN BALADO B, TRUJILLO RODRÍGUEZ C. (1998) Los cambios estructurales en la agricultura cubana. Recuperado de http://lasa.international.pitt.edu/LASA98/PampinBalado-TrujilloRodriguez.pdf.

PAVEL VIDAL A. (2010) Los cambios estructurales e institucionales. En Centro de Estudios de la Economía Cubana, Universidad de la Habana. Recuperado de http://thecubaneconomy.com/wp-content/uploads/2011/12/Los-cambios-estructurales-einstitucionales.-Pavel-Vidal_0.pdf.

PAVÓ ACOSTA R. (2010) La reforma agraria en Cuba; del Programa de la Joven Cuba a la Ley de 17 de mayo de 1959. En Revista Santiago, nº121, pp. 227-249.

PÉREZ ROJAS N.; ECHEVARRÍA LEÓN D. (2006) Las Unidades Básicas de Producción Cooperativa cubanas (1993-2003). Análisis para un debate. En Hubert C. Grammont La construcción de la democracia en el campo latinoamericano, pp. 243-259. Buenos Aires: CLACSO, Consejo Latinoamericano de Ciencias Sociales.

PÉREZ VILLANUEVA O.E. (2009) La estrategia económica cubana: medio siglo de socialismo. En Cahiers des Amériques latines, no 57-58, pp. 31-55.

PÉREZ VILLANUEVA O.E. (2010) Notas recientes sobre la economía de Cuba. En Espacio Laical, vol. 6, n 3, pp. 75-81.

Recuperado de http://www.espaciolaical.org/contens/23/7581.pdf.

PIÑEIRO HARNECKER C. (2012) Visiones sobre el socialismo que guían los cambios actuales en Cuba. En Temas, $\mathrm{n}^{\circ}$ 70, pp. 46-55. Recuperado de http://www.temas.cult.cu/revistas/70/046-055\%20Camila.pdf.

RAZETO MIGLIARO L. (1982) Empresa de Trabajadores y Economía de Mercado. Santiago: Ediciones PET.

RODRÍGUEZ J.L (2014a 21 de noviembre) Cuba no se está proponiendo un socialismo de mercado. La Jornada. Recuperado de http://www.jornada.unam.mx/ultimas/2014/11/21/201ccuba-no-se-esta-proponiendo-unsocialismo-de-mercado201d-jose-luis-rodriguez-3692.html.

RODRÍGUEZ J.L. (2014b) Cuba: algunos resultados macroeconómicos visibles de la política económica actual en http://www.cubacontemporanea.com/noticias/11665-cuba-algunos$\underline{\text { resultados-macroeconomicos-visibles-de-la-politica-economica-actual- }}$ i\#sthash.SnVP2c5o.dpuf. 
RODRÍGUEZ R.C. (1978) Cuba en el tránsito al socialismo 1959-1963, México: Edit. Siglo XXI.

RODRÍGUEZ-MUSA O. (2012) La cooperativización en la economía cubana. Aproximación a sus actuales directrices constitucionales. En Revista Avances, vol. 14, nº 4, pp. 313-330.

ROTHSCHILD J. (2009) Workers' Cooperatives and Social Enterprise. A Forgotten Route to Social Equity and Democracy. En American Behavioral Scientist, vol. 52, nº 7, pp. 10231041 DOI: $10.1177 / 0002764208327673$.

SANCHEZ BAJO C., ROELANTS B. (2011) Capital and the Debt Trap - learning from cooperatives in the global crisis, Palgrave Macmillan.

TRIANA J. (2011) El período especial, veinte años después. En Temas, nº 65, pp. 59-75, Recuperado de http://medicablogs.diariomedico.com/estvez/files/2010/12/059-Mesa.pdf.

VI Congreso del Partido Comunista de Cuba (2011a) Lineamientos de la Política Económica y Social del Partido y la Revolución. Recuperado de http://www.cubadebate.cu/wpcontent/uploads/2011/05/folleto-lineamientos-vi-cong.pdf.

VI Congreso del Partido Comunista de Cuba (2011b) Información sobre el resultado del Debate de los Lineamientos de la Política Económica y Social del Partido y la Revolución. Recuperado de http://www.cubadebate.cu/wp-content/uploads/2011/05/tabloide_debate_lineamientos.pdf. 